\title{
Taxonomic study of genus Peucela Ragonot, I89 I (Lepidoptera, Pyralidae) in China, with descriptions of three new species
}

\author{
Mujie Qi', Xinghai Zuo', Houhun $\mathrm{Li}^{\prime}$ \\ I College of Life Sciences, Nankai University, Tianjin, China \\ Corresponding author: Houhun Li (lihouhun@nankai.edu.cn)
}

Academic editor: B. Landry | Received 16 July 2020 | Accepted 3 September 2020 | Published 20 October 2020

http://zoobank.org/FDC569A5-9FC4-486C-A6E6-176AA96401DF

Citation: Qi M, Zuo X, Li H (2020) Taxonomic study of genus Peucela Ragonot, 1891 (Lepidoptera, Pyralidae) in China, with descriptions of three new species. ZooKeys 976: 147-158. https://doi.org/10.3897/zookeys.976.56402

\begin{abstract}
The genus Peucela Ragonot, 1891 from China is revised. Three species are described as new to science, $P$. acutativalva sp. nov., $P$. baishanzuensis sp. nov., and $P$. nigra sp. nov. In addition, $P$. olivalis comb. nov. is newly combined. Photographs of adults, and male and female genitalia are provided. A key to the species of Peucela in China is also provided.
\end{abstract}

\section{Keywords}

key, morphology, Pyralinae, Pyraloidea

\section{Introduction}

The genus Peucela Ragonot, 1891 (Pyralidae, Pyralinae) was described with Pyralis pallivittata Moore, 1888 from India as the type species. Warren (1896) described $P$. fumosalis and P. rubrifuscalis from India. Later, the same author, Warren (1897) described P. zonalis from South Africa. Viette (1951) and Marion (1955) described P. bourgini and $P$. ignealis from Madagascar, respectively. Leraut (2010) established the new genus Goateria Leraut, 2010 and transferred P. bourgini to this genus. Leraut (2011) transferred P. ignealis to the genus of Zitha Walker, 1865. To date, the genus Peucela is 
comprised of three valid species, which occur in South Africa and Asia (Moore 1888; Warren 1896, 1897; Nuss et al. 2020). In this study, the genus Peucela from China is reviewed, including descriptions of three new species and one new combination. The generic characters of Peucela are given in detail, and a key to Chinese species based on male genitalia characters is provided.

\section{Material and methods}

The examined specimens were collected with light traps and the dissections of genitalia were prepared by following the methods introduced by Li (2002). Wing venation preparations were carried out by following the protocol of Li and Zheng (1996). Specimens were examined using an Olympus SZX16 stereomicroscope. Images of adults and genitalia were captured with a Leica M205A stereomicroscope and a Leica DM750 microscope plus Leica Application suite 4.2 software. Terminology follows Slamka (2006) and $\mathrm{Li}$ and $\mathrm{Li}$ (2009). All specimens examined, including the types of the new species, are deposited in the Insect Collection of Nankai University (NKU), Tianjin, China.

\section{Taxonomy}

\section{Genus Peucela Ragonot, 1891}

Peucela Ragonot, 1891: 47. Type species: Pyralis pallivittata Moore, 1888.

Generic characters. Adult. Wingspan 19.0-26.5 mm. Frons rounded. Vertex covered with erect scales. Labial palpus upturned, third segment short and slightly porrect (Figs 1,2). Maxillary palpus with three segments, usually as long as third segment of labial palpus and extending beyond its first segment. Antenna with scape dilated or ovate, flagellum filiform. Forewing ground color yellowish brown or grayish brown, with basal and terminal areas darker than median area. Hindwing concolorous with forewing, ante- and postmedial lines conspicuous. Venation (Fig. 3): forewing with 12 veins, $R_{3}$ and $R_{4}$ stalked from $2 / 5$ length of $R_{3}, R_{5}$ stalked with $R_{3+4}$ at basal $1 / 4, R_{3+4+5}$ and $M_{1}$ connate at upper angle of cell, $M_{2}$ and $M_{3}$ connate at lower angle of cell, $1 A+2 A$ furcated at base; hindwing with 10 veins, $S_{c}+R_{1}$ and Rs adjacent at middle of $S_{c}+R_{1}$, Rs and $M_{1}$ shortly stalked at upper angle of cell, $M_{2}$ and $M_{3}$ connate at lower angle of cell.

Male genitalia. Uncus trapezoidal or at least nearly trapezoidal basally. Gnathos with lateral arms bandlike, sinuous or straight; distal process short and hooked; two free basal extensions from base of gnathos, rod-shaped or band-shaped, sometimes enlarged or distally lobe-shaped. Valva broadest at base, narrowed towards apex; sacculus well developed. Juxta oval or shield-shaped. Saccus U-shaped, rounded at apex. Phallus medially curved, with basal part slightly enlarged, distal part cylindrical and granular on inner surface; cornutus thorn-shaped, sometimes basally or medially furcate. 
Female genitalia. Papillae anales ovate. Apophyses posteriores shorter than apophyses anteriores. Antrum sclerotized; colliculum usually sclerotized, folded laterally. Ductus bursae slim, several times as long as corpus bursae, usually granular on inner surface anteriorly. Corpus bursae rounded, signum present or absent.

Diagnosis. The genus Peucela superficially resembles Fujimacia Marumo, 1939 in having a similar wing pattern. It can be distinguished from Fujimacia by having the uncus without a basolateral process at the base (with one basolateral process on each side at base in Fujimacia), the gnathos having two rod-shaped or band-shaped basal extensions (without basal extension in Fujimacia), and the valva without a spine-like process at the apex (with a small spine-like process at the apex) in the male genitalia. Peucela is also similar to Maradana Moore, 1884, but it can be distinguished by having the uncus basally trapezoidal (conical in Maradana), the distal process of the gnathos rather tiny and hooked (distal process of gnathos usually about half as long as lateral arms in Maradana), and the phallus slightly enlarged basally (evenly cylindrical in Maradana) in the male genitalia.

\section{Key to the species of Peucela in China based on male genitalia}

1 Valva distally curved; basal extension of gnathos not enlarged or lobe-shaped

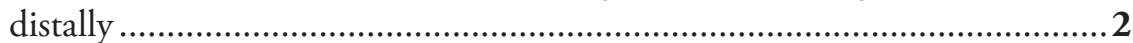

- Valva distally not curved; basal extension of gnathos enlarged or lobe-shaped

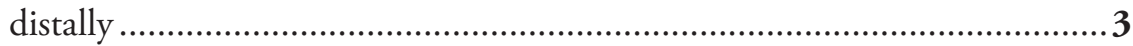

2 Uncus trapezoidal; gnathoas with lateral arms about half as long as basal extensions; valva rounded at apex (Fig. 9).............. P. baishanzuensis sp. nov.

- Uncus basally trapezoidal; gnathoas with lateral arms as long as basal extensions; valva triangular at apex (Fig. 8) ......................P. acutativalva sp. nov.

3 Uncus with apex about $1 / 3$ width of basal width; lateral arms of gnathos as long as its basal extension (Fig. 10) .................................... P. nigra sp. nov.

- Uncus with apex about $1 / 2$ width of basal width; lateral arms of gnathos about 1.5 times as long as its basal extension (Fig. 11) P. olivalis

\section{Peucela acutativalva Qi \& Li, sp. nov.}

http://zoobank.org/04E42A7F-C659-4545-B026-0A2C8C05F3B1

Figs $1,2,4,8,12$

Type material. China, Tibet: Holotype, ${ }^{\lambda}$, Langjiu Village $\left(28.40^{\circ} \mathrm{N}, 85.35^{\circ} \mathrm{E}\right)$, Gyirong County, 2772 m, 11.VII.2019, leg. Mujie Qi, Jiaqi Deng, genitalia slide No. QMJ19027.

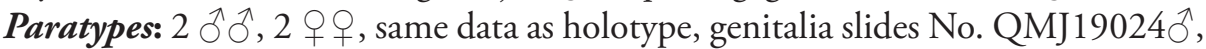

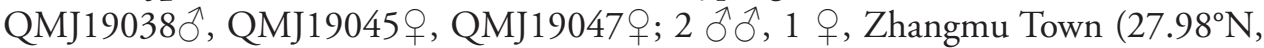
$85.97^{\circ} \mathrm{E}$ ), Nyalam County, $1961 \mathrm{~m}, 5-8$. VII.2019, leg. Mujie Qi, Jiaqi Deng, geni-

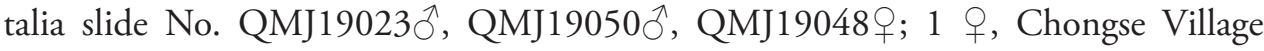
$\left(28.38^{\circ} \mathrm{N}, 85.36^{\circ} \mathrm{E}\right)$, Gyirong County, $2640 \mathrm{~m}, 14 . V I I .2019$, leg. Mujie Qi, Jiaqi Deng, genitalia slide No. QMJ19039. 


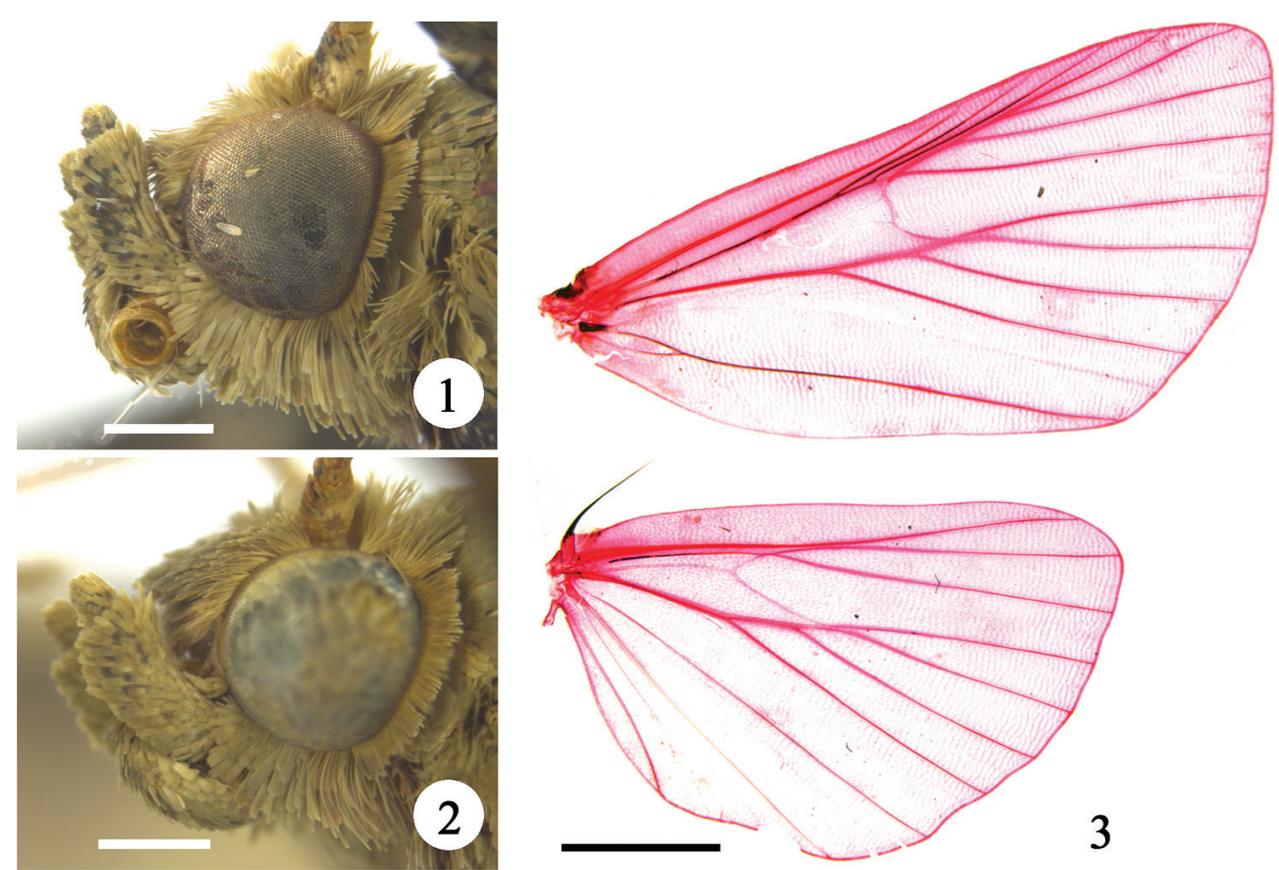

Figures I-3. Morphology of Peucela spp. I head of $P$. acutativalva, sp. nov., $0 \mathbf{2}$ head of $P$ acutativalva, sp. nov., +3 venation of $P$. nigra sp. nov., slide No. QMJ15128w. Scale bars: $0.5 \mathrm{~mm}(\mathbf{I}, \mathbf{2}) ; 2.5 \mathrm{~mm}(\mathbf{3})$.

Diagnosis. This species is similar to P. pallivittata (Moore, 1888) in the male genitalia, but it can be distinguished from the latter by the valva sharp at apex, the gnathos with the basal extension as long as the lateral arms, and the cornutus furcated at basal $1 / 3$. In $P$. pallivittata, the valva is rounded at apex, the basal extension of the gnathos is about half the length of the lateral arms, and the cornutus is not furcated basally.

Description. Adult (Fig. 4). Wingspan 22.0-23.5 mm. Frons and vertex yellowish brown. Labial palpus yellowish brown, slightly mixed with fuscous scales; first segment about $1 / 3$ length of second; second segment upturned; third segment as long as first. Maxillary palpus with first segment as long as third; second segment with constriction medially, extending strongly beyond first segment of labial palpus; concolorous with labial palpus. Male antenna with scape ovate, flagellum ventrally ciliate. Patagium and tegula yellowish brown. Forewing grayish brown; basal area fuscous except for grayish brown at posterior half; terminal area fuscous, slightly mixed with reddish brown scales; costal margin fuscous except for median area interrupted with pale grayish brown spots; antemedial line pale grayish brown, from basal $1 / 4$ of costa to basal $1 / 3$ of dorsum, anterior half arched outwardly, posterior half concave inwardly; postmedial line concolorous with antemedial, edged with fuscous line on inner side, from distal $2 / 5$ of costa to distal $1 / 8$ of dorsum sinuously, with a distinct pointed convex between vein $M_{1}$ and $M_{2}$; median area sparsely suffused with fuscous scales, distal discoidal 

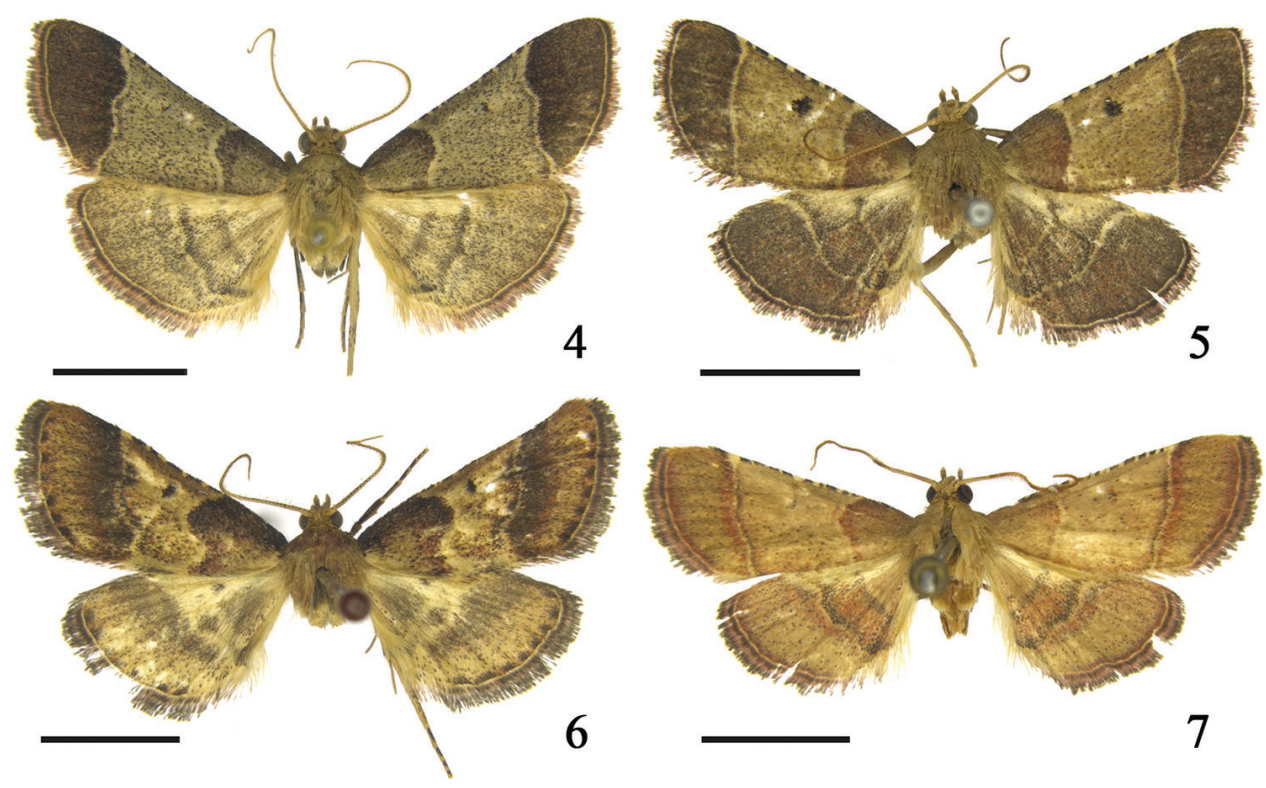

5

Figures 4-7. Adults of Peucela spp. 4 P. acutativalva, sp. nov., holotype, $0 \mathbf{5}$ P. baishanzuensis, sp. nov.,

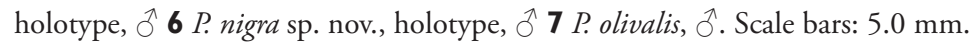

stigma fuscous; cilia fuscous at basal half, reddish brown at distal half. Hindwing concolorous with median area of forewing; ante- and postmedial lines pale grayish brown, both arched outwardly, outer side of antemedial and inner side of postmedial lines edged with fuscous lines; cilia fuscous at base, reddish brown distally. Foreleg fuscous except for tibia slight mixed with yellowish brown and each tip of tarsomere yellowish brown; midleg fuscous except for distal tibia and each apex of tarsomere yellowish brown; hindleg with femur fuscous, tibia and tarsus fuscous suffused with yellowishbrown scales, tarsus with scattered yellowish-brown scales, each tarsomere with apex yellowish brown.

Male genitalia (Fig. 8). Uncus with basal 3/5 trapezoidal, distal 2/5 oblong, with tiny triangular process at apex. Gnathos basally crescent-shaped, with a slim and upturned hook apically about $1 / 10$ as long as uncus; basal extension rod-shaped, as long as lateral arms, slightly inflated distally. Valva broad basally, gradually narrowed towards triangular apex, ventral margin curved at apex, dorsal margin with flat triangular projection at distal $1 / 4$ of valva. Sacculus broad at base, gradually tapered distally, about $3 / 5$ as long as valva. Juxta shield-shaped. Saccus U-shaped, distal 1/4 slightly narrowed. Phallus with basal half oval, distal half cylindrical and granular; cornutus about $1 / 4$ length of phallus, furcated at basal $1 / 3$, furcated part about $1 / 5$ as long as cornutus.

Female genitalia (Fig. 12). Papillae anales ovate. Apophyses anteriores gradually tapered toward apex, about 3 times as long as apophyses posteriores. Antrum sclerotized, as long as apophyses anteriores; colliculum well sclerotized, slightly folded 

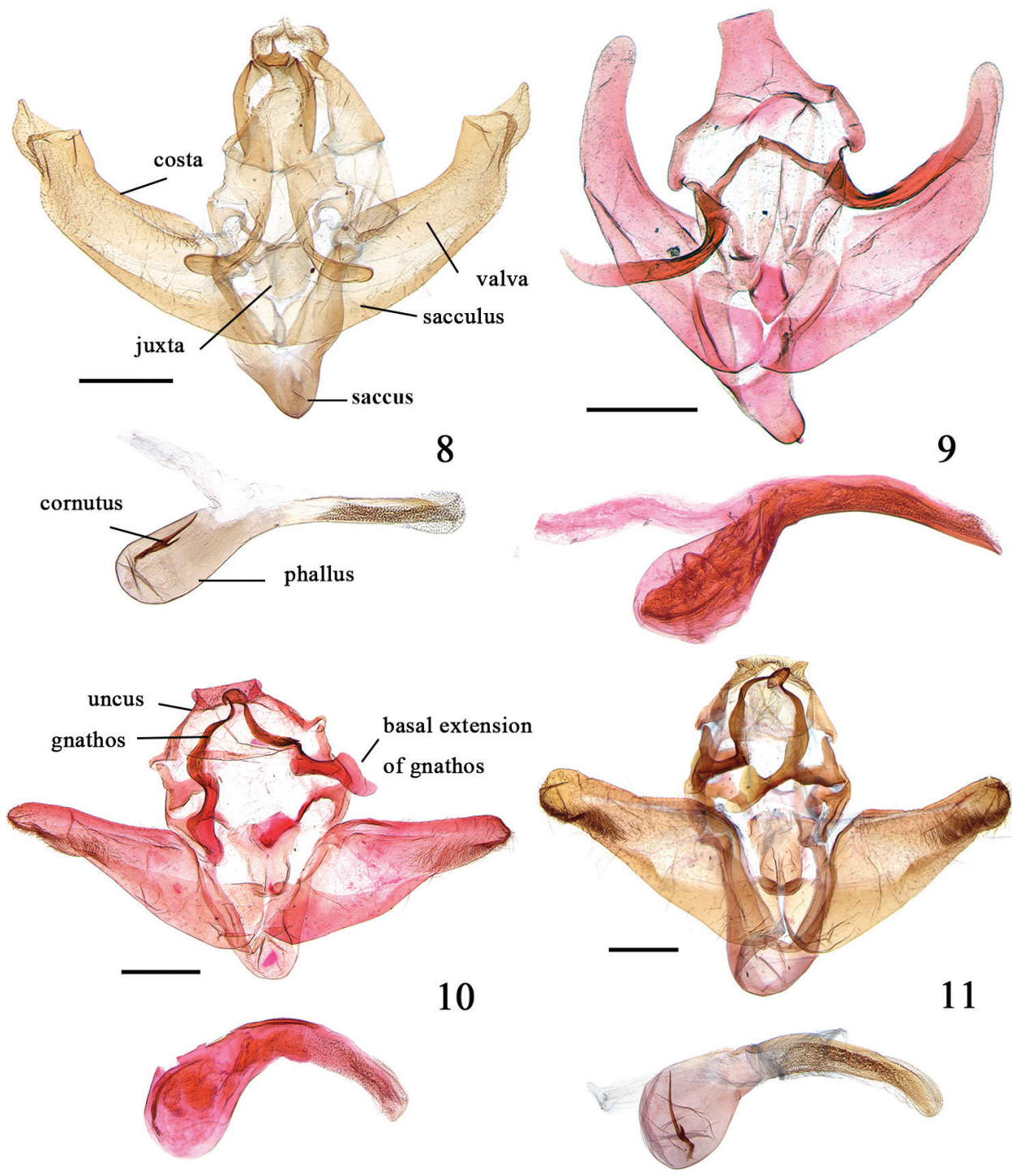

Figures 8-I I. Male genitalia of Peucela spp. 8 P. acutativalva, sp. nov., paratype, slide No. QMJ19023 9 P. baishanzuensis, sp. nov., holotype, slide No. LJ17121 I0 P. nigra sp. nov., holotype, slide No. LJ17056 I I P. olivalis, slide No. QMJ19029. Scale bars: $0.5 \mathrm{~mm}$.

laterally, about as long as or slightly shorter than antrum. Ductus bursae with basal half wrinkled, anterior half granular on inner side, about 3 times as long as corpus bursae. Corpus bursae rounded; signum absent.

Etymology. The specific name is derived from the Latin acutatus (tapered) and valva (valva), in reference to the shape of the valva at the apex in the male genitalia.

Distribution. China (Tibet). 


\section{Peucela baishanzuensis Qi \& Li, sp. nov.}

http://zoobank.org/EC73F1FE-785F-4EB0-8F0A-456C41A975B1

Figs 5, 9

Type material. China, Zhejiang Province: Holotype, $\widehat{\partial}$, Baishanzu Nature Reserve $\left(27^{\circ} 44^{\prime} \mathrm{N}, 119^{\circ} 10^{\prime} \mathrm{E}\right)$, Qingyuan County, 1149 m, 15.VIII.2016, leg. Qingyun Wang, Meiqing Yang, Ping Liu, genitalia slide No. LJ17121.

Diagnosis. This species is superficially most similar to $P$. olivalis, but the male genitalia can be distinguished from that species in having the trapezoidal uncus not folded laterally at the apex, and the short and straight lateral arms of the gnathos about half as long as the basal extension, which is sharp and lacks an inflated triangular lobe distally. In P. olivalis, the uncus is basally semicircular, distally rectangular, and laterally folded at the apex; the lateral arms of the gnathos are arched and as long as the basal extension, which is inflated and distally lobe-shaped, and rounded at the apex.

Description. Adult male (Fig. 5). Wingspan $25.0 \mathrm{~mm}$. Frons and vertex yellowish brown. Labial palpus yellowish brown; first segment as long as third, about 1/4 length of second. Maxillary palpus yellowish brown, as long as third segment of labial palpus; extending slightly beyond first segment of labial palpus. Antenna of male with scape dilated; flagellum ventrally with cilia. Patagium and tegula pale grayish brown. Forewing grayish brown; basal area with anterior $1 / 3$ fuscous along costa, posterior $2 / 3$ pale reddish brown except basal area pale brown; median area pale brown, with scattered fuscous scales; terminal area fuscous, mixed with reddish brown scales; costal margin fuscous, interrupted by yellowish-brown spots at median area; antemedial line pale yellowish brown, arched outwardly from basal $1 / 4$ of costa to basal $1 / 3$ of dorsum; postmedial line concolorous with antemedial line, edged with fuscous line both on inner and outer sides, from distal $1 / 4$ of costa to distal 1/6 of dorsum sinuously; distal discoidal stigma fuscous; cilia fuscous at base, distally reddish brown. Hindwing fuscous mixed with reddish brown scales; ante- and postmedial lines yellowish brown and sinuous; postmedial line with posterior half incurved inwardly, approximated to antemedial line at dorsum; cilia same as that in forewing. Foreleg fuscous except each apex of tarsomere yellowish brown; midleg with femur fuscous, tibia yellowish brown except basal half and apex fuscous, tarsus yellowish brown, suffused basally with fuscous scales; hindleg yellowish brown, femur suffused with fuscous scales, basal of spurs and tarsomere fuscous.

Male genitalia (Fig. 9). Uncus trapezoidal, flat at apex, laterally concave at distal 1/3. Gnathos with lateral arms slim and straight; distal process tiny and rhombic; basal extension upturned at basal 1/4, about twice as long as lateral arms of gnathos, knife-shaped at apex. Valva broad basally, gradually narrowed towards rounded apex; clasper flat, at below base of costa; sacculus gradually tapered distally, about 3/5 length of valva. Juxta with basal part sclerotized and rhombic, apical part membranous and rectangular. Saccus U-shaped, rounded at apex, about 1/3 length of sacculus. Phallus with basal part oval; distal part about 1.2 times as long as basal part, distally with granules; cornutus about $1 / 5$ length of phallus. 

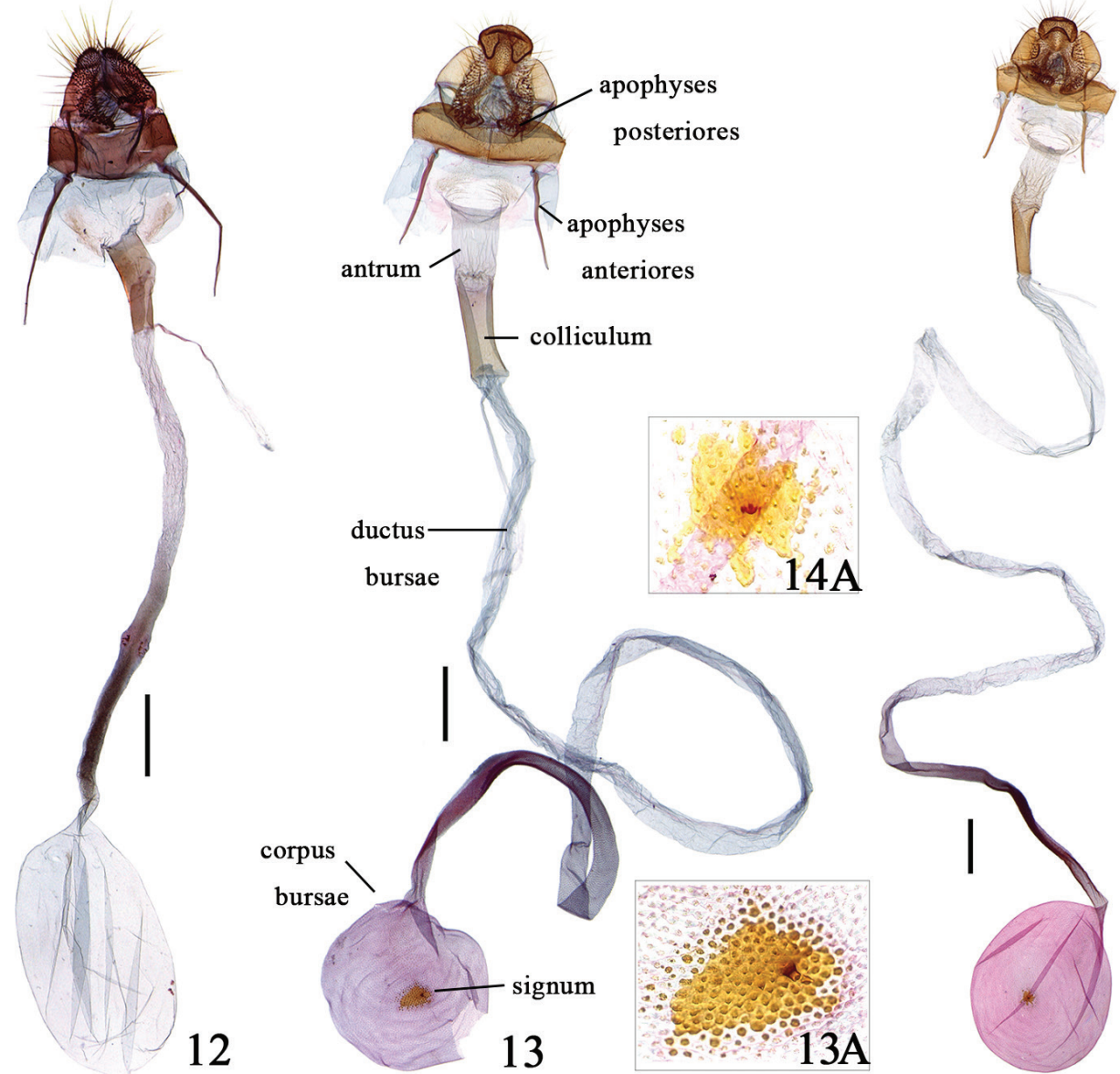

14

Figures 12-14. Female genitalia of Peucela spp. 12 P. acutativalva, sp. nov., paratype, slide No. QMJ19048 13 P. nigra sp. nov., paratype, slide No. QMJ15128 I3A Enlarged signum I4 P. olivalis, slide No. QMJ15152 I4A Enlarged signum. Scale bars: $0.5 \mathrm{~mm}$.

Female. Unknown.

Etymology. The specific name is derived from the type locality, Baishanzu Nature Reserve in Qingyuan County, Zhejiang Province.

Distribution. China (Zhejiang).

\section{Peucela nigra Qi \& Li, sp. nov.}

http://zoobank.org/7C7F8047-04B4-4E42-BE04-7C0A915BBF5B

Figs 6, 10, 13

Type material. China, Yunnan Province: Holotype: ${ }^{\top}, \mathrm{Mt}$. Jizu $\left(25.96^{\circ} \mathrm{N}, 100.39^{\circ} \mathrm{E}\right)$, Dali City, 2228 m, 27.VII.2014, leg. Kaijian Teng, Wei Guan, Xiuchun Wang, Shurong Liu, genitalia slide No. LJ17056. 
Paratypes: $2 \uparrow q$, same data as holotype, genitalia slides No. QMJ15128, LJ17057; 1 ㅇ, Lingbaoshan Forestry Park, Nanjian County, 2338 m, 25.VIII.2015, leg. Kaili Liu, Jingxia Zhao, genitalia slide No. QMJ19026.

Diagnosis. This species is similar to $P$. olivalis in the male and female genitalia, but it can be distinguished in the male genitalia by the uncus with the apical width about $1 / 3$ of the basal width and the lateral arms of the gnathos as long as the basal extension and knife-shaped at apex; and in the female genitalia by the antrum as long as the colliculum and the corpus bursae about $1 / 10$ as long as the ductus bursae. In $P$. olivalis, the apex of the uncus is about $1 / 2$ width of its basal width, the lateral arms of the gnathos is 1.5 times as long as its basal extension, and is rounded at apex (Fig. 11); the antrum is longer than the colliculum and the corpus bursae is about $1 / 8$ the length of ductus bursae (Fig. 14).

Description. Adult (Fig. 6). Wingspan 23.0-26.5 mm. Frons and vertex covered with yellowish-brown scales. Labial palpus yellowish brown; second and third segments mixed ventrally with fuscous scales; first segment as long as third; second segment about 5 times as long as first; third segment porrect. Maxillary palpus yellowish brown, slightly shorter than third segment of labial palpus, extending slightly beyond first segment of labial palpus. Antenna with scape ovate, flagellum ventrally with cilia in male. Patagium reddish brown, with scattered fuscous scales; tegula grayish brown. Forewing yellowish brown; basal area with anterior half fuscous, mixed with reddish brown, posterior half grayish brown except for outer margin reddish brown and slightly mixed with fuscous; terminal area with basal half fuscous, outer margin reddish brown, apical half brown, slightly mixed with reddish brown and fuscous; terminal line fuscous with interrupted by reddish brown spots; costal margin fuscous except apex brown, interrupted by yellowish brown spots at median area; antemedial line pale yellowish brown, from basal $2 / 5$ of costa to basal $1 / 3$ of dorsum sinuously; postmedial line bounded by slim, fuscous line on inner side, waved from distal $2 / 5$ of costa to distal $1 / 3$ of dorsum; median area with scattered fuscous and reddish-brown scales, distal discoidal stigma fuscous; cilia fuscous except yellowish brown at base. Hindwing pale grayish brown, terminal area yellowish brown; ante- and postmedial lines yellowish brown, both sinuous; median area with anterior half yellowish brown, posterior half pale grayish brown, interrupted by yellowish-brown spots; cilia concolorous with forewing. Foreleg fuscous except each apex of tarsomere brown; midleg fuscous except behind spur and apex of tarsomere brown; hindleg fuscous, femur slightly mixed with yellowish scales, basal of tibia suffused with brown scales, each distal half of tarsomere brown.

Male genitalia (Fig. 10). Uncus with basal $4 / 5$ semicircular; distal 1/5 rectangular, flat at apex, dorsally setose, ventrally with lobe-shaped process. Gnathos with lateral arms sinuous, distal process beaklike; basal extension as long as lateral arms, basal half straight, distal half dorsally with triangular dilatation. Valva basally broad, gradually narrowed towards truncated apex, setose at distal $2 / 5$ of ventral margin of valva. Sacculus near subtriangular, about $2 / 3$ as long as valva. Juxta with basal half ovate, distal part inverted trapezoidal. Saccus U-shaped, about $1 / 4$ length of sacculus. Phallus with basal $1 / 3$ oval; distal part about twice as long as base, apically gradually narrowed, with granules at distal $4 / 5$; cornutus about $1 / 3$ length of phallus. 
Female genitalia (Fig. 13). Papillae anales with anterior $4 / 5$ ovate, posterior $1 / 5$ diamond-shaped. Apophyses anteriores gradually tapered toward apex, about 3 times as long as apophyses posteriores. Antrum about 4/5 length of apophyses anteriores; colliculum well sclerotized, laterally folded, about as long as apophyses anteriores. Ductus bursae about 10 times as long as corpus bursae, anterior 1/3 scobinate on inner surface. Corpus bursae rounded, scobinate on inner surface; signum consisting of numeral spinules, with short thorn at middle.

Etymology. The specific name is derived from the Latin niger (black) in reference to the dark belt in the distal area of the forewing.

Distribution. China (Yunnan).

\section{Peucela olivalis (Caradja, 1927), comb. nov.}

Figs $7,11,14$

Bostra olivalis Caradja, 1927: 44. TL: China.

Arippara indicator marginata (Walker, 1865): Leraut 2013: 60.

Material examined. Fujian: $1 \curvearrowright$, 1 , Guadun, Mt. Wuyi, 1100 m, 28.VII.2008, leg. Weichun Li, Yongling Sun, Haiyan Bai, genitalia slide No. QMJ17021 ${ }^{\lambda}$, QMJ17022O; Guangxi: $1 \hat{\partial}$, Yangchang Forestry center, Leye County, 1160 m, 26.VII.2004, leg. Jiasheng Xu, genitalia slide No. QMJ16004; Hainan: 1 q, Mt. Diaoluo, 940 m, 31.V.2007, leg. Zhiwei Zhang, Weichun Li, genitalia slide No. LJ17086; 1 Oै, Jianfengling Nature Reserve $\left(18.44^{\circ} \mathrm{N}, 108.52^{\circ} \mathrm{E}\right)$, Ledong County, $770 \mathrm{~m}, 29 . \mathrm{V} .2015$, leg. Peixin Cong, Wei Guan, Sha Hu, genitalia slide No. QMJ19030; Hunan: 1 ô, Zhangjiajie, 650 m, 7.VII.2001, leg. Houhun Li, Xinpu Wang, genitalia slide No. QMJ15197. Sichuan: 1 ô, 2 우, Caoping Village $\left(30.95^{\circ} \mathrm{N}, 103.32^{\circ} \mathrm{E}\right)$, Wenchuan County, 1557 m, 9-12.VII.2014, leg. Kaijian Teng, Wei Guan, Xiuchun Wang, Shu-

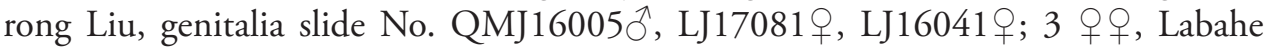
Nature Reserve, Tianquan County, 1300 m, 28-29.VII.2004, leg. Yingdang Ren, genitalia slide No. LJ17078, QMJ15152, LJ17080; Yunnan: 1 đ, Taiyanghe Nature Reserve, 1450m, 2.IX.2014, leg. Zhengguo Zhang, genitalia slide No. LJ16024; Zhejiang: $1 \hat{\jmath}$, Chanyuansi, Mt. Tianmu, $350 \mathrm{~m}, 15$. VIII.1999, leg. Houhun Li et al., genitalia slide No. WSS02136.

Diagnosis. This species shares most of the diagnostic characters of the genus as follows: in male genitalia, gnathos with two free basal extensions at base and phallus medially curved, with basal part enlarged slightly; in female genitalia, colliculum cylindrical and sclerotized and ductus bursae several times as long as rounded corpus bursae and granular anteriorly. Adult (Fig. 7) with wingspan 19.5-22.0 mm. This species is superficially most similar to P. baishanzuensis sp. nov., and the differences between them are stated under $P$. baishanzuensis sp. nov. In addition, it resembles $P$. nigra sp. nov. in the male and female genitalia, and the differences between them are stated in the diagnosis of $P$. nigra sp. nov.

Distribution. China (Fujian, Guangxi, Hainan, Hunan, Sichuan, Yunnan, Zhejiang). 


\section{Acknowledgements}

We express our thanks to Dr P.J. Leraut (Muséum national d'Histoire naturelle, Paris, France) for providing references, and we are grateful to Dr Dandan Zhang (Sun Yat-Sen University, Guangdong, China) and Dr Haili Yu (Northwest University, Xi'an, China) for providing some specimens. We are grateful to Dr Alma Solis (Smithsonian Institution, Washington, DC, USA) for the review and linguistic assistance on the manuscript before submission, and we give our cordial thanks to Frantisek Slamka (Frantisek Slamka Publisher, Slovakia) and Bernard Landry (Muséum d'histoire naturelle de Genève, Geneva, Switzerland) for their kind comments and suggestions. Cordial thanks also go to Dr Zhaohui Pan (Institute of Plateau Ecology, Xizang Agriculture and Animal Husbandry University, Xizang [Tibet], China) for the help during the collecting trips in Tibet. This study was supported by the National Natural Science Foundation of China (No. 31601883, 31660625).

\section{References}

Caradja A (1927) Die Kleinfalter der Stötzner'schen Ausbeute, nebst Zuträge aus meiner Sammlung (Zweite biogeographische Skizze: „Zentralasien“). Mémoriile Sectiunii Stiintifice, Academia Romana 4(8): 361-428.

Leraut PJA (2010) Étude d'un nouveau genre des pyrales (Lepidoptera, Pyraloidea). Revue française d'Entomologie (N.S.) 31(3-4) [2009]: 139-152.

Leraut PJA (2011) Nouvelles espèces et nouveau genre de Pyralidae (Lepidoptera, Pyraloidea). Revue française d'Entomologie (N.S.) 32(1-2) [2010]: 33-58.

Leraut PJA (2013) Espèces et genres nouveaux de Pyralinae (Lepidoptera, Pyraloidea, Pyralidae). Bulletin de la Société entomologique de France 118(1): 41-72.

Li HH (2002) The Gelechiidae of China (I) (Lepidoptera: Gelechioidea). Nankai University Press, Tianjin, $538 \mathrm{pp}$.

Li HH, Li WC (2009) Pyralinae. In: Li HH, Ren YD (Eds) Insect Fauna of Henan (Lepidoptera: Pyraloidea). Science Press, Beijing, 36-57.

Li HH, Zheng ZM (1996) Methods and techniques of specimens of microlepidoptera. Journal of Shaanxi Normal University 24(3): 63-70.

Marion H (1955) Pyrales nouvelles de Madagascar. Bulletin de la Société entomologique de France 60: 114-119.

Marumo N (1939) Studies on rice borers IV. Classification of the subfamily Pyralinae in Japan. Nozikairyosiryo 142: 1-40.

Moore F (1884) The Lepidoptera of Ceylon (Vol. 3). L. Reeve, London, 578 pp.

Moore F (1888) Heterocera (continued) (Pyralidae, Crambidae, Geometridae, Tortricidae, Tineidae). In: Hewitson WC, Moore F (Eds) Descriptions of new Indian lepidopterous Insects from the collection of the late Mr. W.S. Atkinson 3. Asiatic Society of Bengal, London, 199-299.

Nuss M, Landry B, Mally R, Vegliante F, Tränkner A, Bauer F, Hayden J, Segerer A Schouten R, Li H, Trofimova T, Solis MA, De Prins J, Speidel W (2003-2020) Global Information System on Pyraloidea. http://www.pyraloidea.org [Accessed on: 2020-5-1] 
Ragonot EL (1891) Essai sur la classification des Pyralites (suite). Annales de la Société entomologique de France 60(1): 15-114.

Slamka F (2006) Pyraloidea of Europe (Vol. 1) (Pyralinae, Gallerinae, Epipaschiinae, Cathariinae $\&$ Odontiinae). Frantisek Slamka, Bratislava, 138 pp.

Viette P (1951) Quelques microlépidoptères de Madagascar. Mémoires de l'Institut scientifique de Madagascar, Série A 5(2): 335-347.

Walker F (1865) List of Specimens of Lepidopterous Insects in the Collection of the British Museum. Part XXXIV. Supplement.-Part4. Trustees of the British Museum, London, 1121-1534.

Warren W (1896) New species of Pyralidae from the Khasia Hills. Annals and Magazine of Natural History, including Zoology, Botany and Geology (series 6) 17: 452-466. https:// doi.org/10.1080/00222939608680398

Warren W (1897) New genera and species of moths from the old-world regions in the Tring Museum. Novitates Zoologicae 4: 12-130. https://doi.org/10.5962/bhl.part.21182 